\title{
Change in well-being amongst participants in a four-month pedometer-based workplace health program
}

\author{
Rosanne LA Freak-Poli ${ }^{1,2,3^{*}}$, Rory Wolfe ${ }^{2}$, Evelyn Wong ${ }^{1,2}$ and Anna Peeters ${ }^{1,2}$
}

\begin{abstract}
Background: There is increasing uptake of workplace physical activity programs to prevent chronic disease. While they are frequently evaluated for improvement in biomedical risk factors there has been little evaluation of additional benefits for psychosocial health. We aimed to evaluate whether participation in a four-month, team-based, pedometer-based workplace health program known to improve biomedical risk factors is associated with an improvement in well-being, immediately after the program and eight-months after program completion.

Methods: At baseline (2008), 762 adults (aged $40 \pm 10$ SD years, 42\% male) employed in primarily sedentary occupations and voluntarily enrolled in a physical activity program were recruited from ten Australian worksites. Data was collected at baseline, at the completion of the four-month program and eight-months after program completion. The outcome was the WHO-Five Well-being Index (WHO-5), a self-administered five-item scale that can be dichotomised as 'poor' (less than 52\%) or 'positive' (more than or equal to 52\%) well-being.

Results: At baseline, 75\% of participants had positive well-being (mean: $60 \pm 19$ SD WHO-5 units). On average, well-being improved immediately after the health program $(+3.5$ units, $p<0.001)$ and was sustained eight-months later (+3.4 units from baseline, $p<0.001$ ). In the $25 \%$ with poor well-being at baseline, $49.5 \%$ moved into the positive well-being category immediately after program completion, sustained eight-months later $(p<0.001)$.

Conclusions: Clinically relevant immediate and sustained improvements in well-being were observed after participation in the health program. These results suggest that participation in workplace programs, such as the one evaluated here, also has the potential to improve well-being.
\end{abstract}

Keywords: Well-being, Happiness, Workplace, Intervention, Evaluation, Physical activity, Prevention

\section{Background}

The World Health Organization defines health as "a state of complete physical, mental and social well-being and not merely the absence of disease or infirmity" [1]. As physical activity has been reported to be associated with antidepressant effects [2-4], improved mood [3,5], biological resilience to psychosocial stressors [2] and employee psychosocial health [4], an increase in physical activity is likely to have a beneficial effect on mental health. Two theories explaining the underlying mechanisms for the relationship between physical activity and

\footnotetext{
* Correspondence: Rosanne.Freak-Poli@monash.edu

${ }^{1}$ BakerIDI Heart and Diabetes Institute, Melbourne, Australia

${ }^{2}$ Department of Epidemiology \& Preventive Medicine, School of Public Health and Preventive Medicine, Monash University, Melbourne, Australia Full list of author information is available at the end of the article
}

psychosocial health have been discussed. The mechanical theory describes changes in the body that affect stress, for example exercise increases the synthesis of brain-derived neurotropic factor which is associated with stress when levels are low [6,7] and exercise increases body temperature and blood circulation which impacts the hypothalamic-pituitary-adrenal axis and reactivity to stress [3]. The psychological theory relates to selfefficacy and cognitive dissonance. As described by Ikenouchi-Sugita et. al [8], physical activity can relieve feelings of depression, improve social habits and create regular fitness habits which, in turn, improves mood.

A series of physical activity interventions in a range of settings have found beneficial effects for improving mental health and well-being [9-12]. One key setting for 
health promotion is the workplace, where physical activity programs have attempted to counter balance the gradually increasing sedentary nature of occupations [13-16]. In this setting, health programs that incorporate a pedometer have become a popular method of increasing physical activity as they are low-cost, small, light, portable and easy to-use [16]. These pedometer-based health programs generally involve wearing a pedometer and recording each day's number of steps (step-count) $[17,18]$. As pedometer workplace health programs are increasingly being instigated, it is important to evaluate whether these relatively simple health programs offer an avenue for improving population health. To date, variations of pedometer workplace health programs have reported immediate improvements in physical activity, anthropometric outcomes such as waist circumference and blood pressure, and biomedical outcomes such as total cholesterol [13,19-39]. It is also of interest whether pedometer-based workplace health programs improve health and well-being more broadly.

Within the context of a pedometer-based work-place health programs, several program characteristics could potentially improve well-being directly. Firstly, as described above, an increase in physical activity is likely to have a direct beneficial effect on mental health through mechanical theory. Secondly, through psychological theory participating in physical activity the participant may increase awareness of fitness capabilities and may increase self-esteem and willingness to participate in other social activities [40]. Thirdly, the pedometer itself provides specific feedback, promoting self-efficacy through Social Cognitive Theory [16,39,41-47] via progressive individual goal-setting which allows the participant to be flexible in the amount and the scheduling of their physical activity and provide increased control upon one's health [16]. Fourthly, if the program has a team component, it creates a social environment for the participant and collegiate camaraderie $[8,16,46]$. Thereby, social cohesion is increased through a focus upon team-based participation and the endorsement of the program by leaders, through both financial and time support, can reinforce participation in such programs. As both social cohesion and the environment are associated with mental health [48], such programs addressing these characteristics may improve well-being directly. Finally, if the program has a competitive component, it may provide increased self-esteem if the participant does well.

Four pedometer-based workplace health program evaluations have encapsulated some of the broader aspects of health $[8,13,49,50]$. These evaluations have reported differing findings; a decrease in depressive symptoms in previous non-exercisers after a four-week program [8]; no change in Health Related Quality of Life (HRQoL) scales immediately after a nine-week program [13]; an immediate benefit in the mental component of HRQoL after a four-month program [49]; and an immediate benefit by reduction in the number of self-reported physically and mentally unhealthy days after a three-month program, which was sustained fourteen-weeks later [50]. These pedometer workplace health programs have utilised health surveys that either evaluate self-reported depressive symptoms or the impact of positive psychosocial health upon health. It is important to assess general well-being as health promotion programs may have multiple benefits across mental health and well-being and physical health outcomes, not just those related to physical health. General well-being has not previously been evaluated in a pedometer workplace health program.

This paper aimed to evaluate whether participation in a four-month, pedometer-based, workplace health program known to improve biomedical risk factors was also associated with an improvement in well-being. The secondary aim was to identify participant characteristics associated with immediate and long-term improvements in well-being. Potential benefits were assessed immediately after the program (at four-months) and in the longer-term (eight-months after program completion).

\section{Methods}

This paper was undertaken as part of a larger study, tithed the Global Corporate Challenge ${ }^{\circ}\left(\mathrm{GCC}^{\circ}\right)$ Evaluation study $[17,49,51-55]$.

\section{Description of the program}

The $\mathrm{GCC}^{\ominus}$ is a corporate organisation that undertakes a world-wide, annual, four-month (May to September), team-based, visible step-count pedometer, workplace health program. The target is to achieve 10,000 steps per day, which is based upon the World Health Organization's recommendation [56]. Teams of seven employees enter their step-counts to virtually walk around a world map. Weekly encouragement emails are sent in the form of a newsletter which, in 2008, included the participant's personal best daily step count, a weekly health tip from a nutritionist, stories from participants, a "Dear GCC" answer to a participant's question, housekeeping notices and prizes awarded from sponsors. A website was used for logging daily steps, access to additional health information such as the number of steps required to burn off a hamburger, communication among participants and comparing team progress.

\section{$\mathrm{GCC}^{\circledast}$ evaluation recruitment}

In 2008, 259 of the workplaces participating in the GCC had an office located in Melbourne and several were approached by $\mathrm{GCC}^{\circ}$ employees regarding their interest to be study sites for an evaluation. Preference for approaching workplaces was based on early conscription 
to the $\mathrm{GCC}^{\oplus} 2008$ event, a large number of employees, a variety of sedentary occupations, and the availability of a designated $\mathrm{GCC}^{\circledast}$ coordinator. Ten evaluation sites consented, providing access to 4,138 people enrolled in the GCC ${ }^{\ominus}$. Participating workplaces sent internal emails to inform employees of the evaluation and after interest was registered, Monash University staff sent an email with an explanatory statement and consent form. Seven hundred and sixty two voluntary consenting participants, aged 18 years and above and were recruited and assessed in April/May 2008 [52]. GCC ${ }^{\oplus}$ Evaluation study participants were similar to the other employees enrolled in the GCC 2008 at the participating workplaces in terms of age and sex, but were more likely to comply with the step goal [51]. At four-months 79\% returned [17], and at eight-months after program completion $76 \%$ of the original sample returned [51].

\section{Data collection}

Data was collected at baseline, four-months and eightmonths after the completion of the program. An Internet self-report questionnaire incorporated demographic information [57-59] (including age, sex, education, household status, marital status and occupation), motivation and support for participation [57] (including the level of support from workplace) and behavioural measures $[57,59,60]$ (including tobacco use, alcohol consumption, eating behaviour, physical activity, sedentary behaviour and physical functioning). Measurements were collected by trained staff in the morning at the employee's workplaces including blood pressure (using Omron IA1B Automatic blood pressure intellisense machines), height (using a stadiometer portable height scale code PE087 and step ladder), weight (using Salter electronic bathroom scales model 913 WH3R 3007 during baseline and four-month data collection and Seca digital scales model Robusta 813 during twelve-month data collection) and waist and hip measurements (using a Figure Finder Tape Measure Novel Products Inc 2005 code PE024 and a mirror).

\section{Well-being}

Well-being was measured using the validated WHO-Five Well-being Index (WHO-5) [61-65], a self-administered five-item scale that is designed to assess subjective wellbeing. The items cover positive mood (good spirits, relaxation), vitality (being active and waking up fresh and rested), and general interests (being interested in things) $[61,65]$. Each of the five items is rated on a 6-point Likert scale and converted proportionally to a score that ranges from 0 (worst thinkable well-being) to 100 (best thinkable well-being) [61,65]. A score below 52 indicates poor wellbeing and is an indication for testing for depression under
ICD-10 [61]. A 10\% difference in the score indicates a clinically significant change [61].

\section{Variable selection}

To compare differences between those with poor versus positive well-being at baseline, baseline measures and average daily step-count throughout the four-month program were assessed. Several variables were dichotomised as meeting commonly accepted clinical guidelines: physical activity (at least 150 minutes of moderate intensity activity per week) [66-78], fruit (two serves a day) $[66,68,69]$ and vegetable consumption (four serves a day) $[66,68,69]$. Participants were categorised as meeting tobacco guidelines if they did not report currently smoking or chewing tobacco.

Baseline demographic variables, as well as, the process variable of average daily step-count throughout the fourmonth program (indicating compliance with the program) were assessed as potential 'predictors' of wellbeing change in response to the program. Psychosocial measures were not considered 'predictors' of well-being change due to the potential for introducing bias [70].

\section{Analysis}

Unless otherwise indicated, continuous data is summarised as mean \pm standard deviation (SD). Analyses were performed using Stata version 11 [71]. Robust standard errors, clustered by workplace, were used in all statistical analyses. A p-value $<0.05$ was used to determine statistical significance. Pregnant participants during the study timeframe were excluded from all analyses ( $\mathrm{n}=28)$.

\section{Retention}

Participants who did and did not return at four-months or eight-months after program completion were compared according to baseline variables, four-month change variables and average daily step-count data, where relevant.

\section{Well-being change}

Change in well-being after participation in the health program was assessed by analysing the difference between baseline and four-month, and the difference between baseline and eight-month after program completion measurements using linear regression. Analyses of change were also stratified by baseline well-being status. The potential magnitude of the regression to the mean effect on the observed change in well-being was estimated using an established method [72]. Positive well-being was assessed for temporal change through conditional logistic regression with time-point as an explanatory variable, where change from poor to positive well-being was represented by a 0,1 
pair of binary values, and positive to poor was represented by a 1, 0 pair [17].

The primary analysis assessing change in well-being associated with participation in the health program included participants who completed the WHO-5 at the three data collection rounds. A secondary (sensitivity) analysis was undertaken using participants with complete data on the relevant two rounds for each analysis of temporal change.

\section{Variable selection}

Demographic and the process measurement of average daily step count were assessed as potential predictors of immediate and long-term well-being change. Potential predictors were assessed by univariable and multivariable regression analyses with well-being change as the outcome variable.

\section{Ethics}

The study, project number CF08/0271-2008000125, was approved by Monash University Human Research Ethics through the standing committee on ethics in researchinvolving humans.

\section{Results}

\section{Retention}

Of the 734 eligible participants, $93 \%(n=685)$ completed the WHO-5 at baseline, 64\% $(n=468)$ completed the WHO-5 at baseline and four-month and 55\% ( $\mathrm{n}=407)$ completed the WHO-5 at all three time-points.

Those who completed the WHO-5 at all three timepoints were more likely to be older (mean \pm SD: $42 \pm$ 10 years versus $39 \pm 11$ years, $\mathrm{p}=0.002$ ), have a professional position $(68 \%$ versus $54 \%, \mathrm{p}=0.001)$, participate in the $\mathrm{GCC}^{\bullet}$ due to appearance reasons $(61 \%$ versus $54 \%, \mathrm{p}<0.001$ ), not smoke tobacco (92\% versus $86 \%$, $\mathrm{p}=0.004)$, meet baseline physical activity guidelines ( $42 \%$ versus $34 \%, \mathrm{p}=0.03$ ) and undertake more steps during the health program $(11,854 \pm 3,777$ mean steps per day versus $11,111 \pm 3,636, \mathrm{p}=0.02)$.

\section{Distribution of well-being}

At baseline the distribution of well-being was left skewed, with the majority (75\%) being in the positive well-being category. Participants who were older, participating in the $\mathrm{GCC}^{\oplus}$ for health reasons, met fruit and physical activity guidelines, had a higher mental quality of life and had undertaken at least 10,000 steps per day on average during the program were more likely to be in the positive well-being category at baseline, Table 1 .

\section{Immediate and long-term well-being change}

Immediately after the health program, in the 407 participants with complete data at all three time-points, an average improvement of 3.5 units compared to baseline $(\mathrm{p}<0.001)$ was reported and this was sustained eightmonths later $(3.4$ units, $\mathrm{p}<0.001)$, Table 2 . The proportion of participants with positive well-being increased immediately after the program (by 6.2\%, p $<0.001$ ), however in the long-term the magnitude of improvement was smaller and not statistically significant (by $2.5 \%, \mathrm{p}=0.1$ )

\section{Change in well-being stratified by baseline well-being}

In the 407 participants with complete data at all three time-points, no evidence of immediate or long-term change was found for those with positive well-being at baseline (continuous mean change at four-months: -0.3 units, $\mathrm{p}=0.6$; eight-months after program completion: -0.9 units, $p=0.1$ ). Significant immediate and long-term improvement was observed for those with poor wellbeing at baseline (continuous mean change at fourmonths: 14.9 units, $\mathrm{p}<0.001$; eight-months after program completion: 16.1 units, $\mathrm{p}<0.001)$. Consequently half of those with poor well-being at baseline moved into the positive well-being category at four-months (49.5\%, $\mathrm{p}<0.001)$ and this was sustained at eight-months after program completion $(49.5 \%, \mathrm{p}<0.001)$. The expected effect of regression to the mean in the group with positive well-being at baseline was that change would be in a negative direction (mean expected change four-months: -3.7 units, eight-months after program completion: -4.7 units), a greater decrease than observed (as described above), Additional file 1. Within the poor well-being group at baseline, regression to the mean anticipated positive changes (mean expected change four-months: 7.4 units, eight-months after program completion: 9.4 units) but the observed change was of a greater magnitude than anticipated (as described above), Additional file 1.

\section{Sensitivity analysis}

When complete case analysis (four-month $n=468$, eight-months after program completion $\mathrm{n}=496$ ) was undertaken, the magnitude and statistical significance of the changes were similar to the primary analysis; with the attaining of statistical significance for sustained improvement in the proportion with positive well-being (2.5\% from baseline to eight-months after program completion, $\mathrm{p}=0.02$ ), Additional file 2 .

\section{Predictors of well-being improvement}

At four-months, baseline characteristics associated with immediate improvement in well-being were tertiary education and greater number of steps during the program, Table 3. In those with poor well-being at baseline, the characteristics associated with being in the positive wellbeing category at four-months were older age at baseline 
Table 1 Comparison of those with poor and positive well-being at baseline ${ }^{a}$

\begin{tabular}{cccc}
\hline & $\begin{array}{c}\text { Poor well-being } \\
\text { (Mean } \pm \text { SD or } \\
\text { Percentage) }\end{array}$ & $\begin{array}{c}\text { Positive well-being } \\
\text { (Mean } \pm \text { SD or } \\
\text { Percentage) }\end{array}$ & \\
\hline $\mathrm{n}$ & 103 & 304
\end{tabular}

\section{DEMOGRAPHICS}

$\begin{array}{ll}\text { Age (year) } & 39 \pm \\ \text { Male }^{c} & 42.7 \\ \text { Completion of tertiary } & 84.5\end{array}$

education ${ }^{c}$

Marital status

Married or de facto
Widowed,
separated or
divorced
Never married
BASELINE
MEASURES

Prior GCC ${ }^{\oplus}$

Participation ${ }^{c}$

\section{Motivation for participation}

To look my best ${ }^{c} \quad 68.0$

Fitness ${ }^{c}$

Colleagues $^{c}$

Friends or family

$\begin{array}{cc}39 \pm 9 & 43 \pm 10 \\ 42.7 & 44.1 \\ 84.5 & 79.3\end{array}$

Behavioural measures

Fruit Intake (meeting

guidelines)

Vegetable Intake ${ }^{c}$

(meeting guidelines)

Alcohol $^{c}$ (meeting

guidelines)

Non smoker ${ }^{c}$

Physical activityc

(meeting guidelines)

Sitting time (hrs per day)

Weekday
Weekend

Psychosocial measures

Well-being
Well-being ${ }^{c}$ (positive
category)

0.0

$$
8.7 \pm 4.0
$$$$
8.2 \pm 3.5
$$

$5.3 \pm 2.9$

Health related quality of life (SF-12)

\section{Mental health component \\ Physical health} component

$\begin{array}{lcc}38.6 \pm 11.0 & 53.0 \pm 6.1 & <0.001 \\ 50.5 \pm 8.7 & 51.2 \pm 6.9 & 0.5\end{array}$

$69.3 \pm 9.8 \quad<0.001$

100.0

$-$

$$
32.9 \pm 13.1
$$

Table 1 Comparison of those with poor and positive

\begin{tabular}{|c|c|c|c|}
\hline \multicolumn{4}{|l|}{$\begin{array}{l}\text { Anthropometric } \\
\text { measures }\end{array}$} \\
\hline $\begin{array}{l}\text { Systolic blood } \\
\text { pressure }(\mathrm{mmHg})\end{array}$ & $118.1 \pm 12.9$ & $119.6 \pm 14.4$ & 0.4 \\
\hline $\begin{array}{l}\text { Diastolic blood } \\
\text { pressure }(\mathrm{mmHg})\end{array}$ & $79.6 \pm 9.2$ & $80.2 \pm 10.3$ & 0.6 \\
\hline $\begin{array}{l}\text { Heart rate (beats per } \\
\text { minute) }\end{array}$ & $68.6 \pm 8.5$ & $68.4 \pm 10.6$ & 0.8 \\
\hline Weight (kg) & $80.8 \pm 17.4$ & $76.7 \pm 15.2$ & 0.2 \\
\hline Body mass index $\left(\mathrm{kg} / \mathrm{m}^{2}\right)$ & $27.5 \pm 5.0$ & $26.7 \pm 4.7$ & 0.3 \\
\hline Waist circumference & $90.6 \pm 13.0$ & $88.0 \pm 12.2$ & 0.2 \\
\hline \multicolumn{4}{|l|}{ STEP DATA } \\
\hline Steps average (per day) & $11,223 \pm 3,515$ & $12,066 \pm 3,844$ & 0.06 \\
\hline $\begin{array}{l}\text { Meeting } 10,000 \text { steps } \\
\text { on average }{ }^{c} \text { (per day) }\end{array}$ & 63.7 & 71.7 & 0.04 \\
\hline
\end{tabular}
well-being at baseline ${ }^{a}$ (Continued)

${ }^{\mathrm{a}}$ Restricted to participants who attended baseline, four-month and twelve-month data collection.

${ }^{\mathrm{b}}$ Bold highlights statistically significant results.

'The reference group for this binary variable is ' $n o$ '. The reference group data is not shown.

and undertaking more steps during the health program, Table 4.

At eight-months after program completion, baseline characteristics associated with long-term improvement in well-being were younger age and being widowed, separated or divorced, Additional file 3. In those with poor well-being at baseline, the characteristic associated with improvement to the positive well-being category at eightmonths after program completion was being widowed, separated or divorced at baseline, Additional file 4.

\section{Discussion}

In this study of 407 adults employed in primarily sedentary occupations and voluntarily enrolled in a physical activity program, $75 \%$ of participants were achieving positive WHO-5 well-being scores at baseline. On average, well-being improved immediately after the health program and was sustained eight-months later. A substantial benefit was seen in those with poor well-being at baseline, with around $50 \%$ of this group having positive well-being at both four and eight-months after program completion. Achieving a greater number of steps during the program was associated with immediate well-being improvement.

The overall immediate and long-term changes in wellbeing for the total enrolled population were not clinically significant [61]. This is likely to be due to the high rates of positive well-being observed at baseline (75\%). Our mean baseline score of 60 is in the upper range of general population mean scores from various European countries (52 to 68) [73-76] and a group of undergraduate Australian students $($ mean $=52)$ [77]. When results 
were stratified by baseline well-being category, a clinically relevant immediate and long-term benefit was observed for those categorised as having poor well-being at baseline. In a previous analysis assessing potential predictors of immediate improvements in waist circumference in this program, we found, similarly to the current paper, that greater improvement was associated with being in the high-risk category at baseline [54].

The most prominent characteristic associated with improved well-being in the general study population and those with poor baseline well-being was undertaking more steps during the health program. While a few demographic characteristics were associated with wellbeing change, these were not consistent across analyses. As previously discussed, the program may be having the greatest benefit in those with the greatest opportunity to improve, those who have slightly healthier habits that may find it easier to make the small changes required for a visible outcome and those who achieved the step goal of the health program [54].

Two reviews of workplace physical activity interventions reported insufficient evidence to assess general well-being as an outcome. Conn et. al [78] observed non-significant positive benefits of workplace physical activity interventions upon quality of life and mood, however warned that findings be interpreted with caution given the limited number of included studies. A more recent review by Chu et. al [79] also identified only a few studies assessing general well-being as an outcome of physical activity workplace interventions, which did not provide evidence of a benefit. A pending Cochrane review relating to workplace physical activity may provide further insight [80].

As previously discussed, four pedometer workplace health program evaluations have encapsulated broader aspects of health $[8,13,49,50]$. One assessed changes in depressive symptoms [8], while three assessed changes in positive psychosocial factors $[13,49,50]$ utilising $\mathrm{HRQoL}$ scales. Touger-Decker et. al [50] utilised the Centers for Disease Control Healthy Days Surveillance questionnaire (CDC-PDS) [81], which assesses the number of unhealthy days related to self-rated health, physical health, mental health and activity limitations. Puig-Ribera et. al [13] and Harding \& Freak-Poli et. al [49] both utilised the SF-12 [82] which assesses affective influences such as physical and subjective emotional feelings. The WHO-5 [61] utilised in our paper assesses affective influences such as subjective emotional feelings and cognitive influences such as satisfaction with the present. The key difference between the WHO-5 [61] is that it assesses general well-being while the SF-12 [82] and CDC-PDS [81] assesses psychological factors specifically related to physical health. Hence, this is the first time well-being independent of physical health has been assessed in a pedometer-based workplace health program evaluation.

Our results support findings from these prior evaluations focusing on health related outcomes that participation in such programs is associated with improvement in positive psychosocial health, especially in those with lower psychosocial health at baseline. In addition, a positive relationship between improvement in positive psychosocial health and physical activity level during a program has also been previously observed. Touger-Decker et. al [50] reported that participation in their three-month pedometer workplace health program reduced summative unhealthy days by 2.2 days (a $23 \%$ improvement) directly after the program and this was sustained fourteen-weeks later. Puig-Ribera et. al [13] reported no overall change in HRQoL. However, they reported a non-significant relationship between those with the greatest improvements in physical activity also having the greatest improvements in HRQoL directly after the program. In a previous evaluation of this health program, we demonstrated significant improvement in the mental component score (MCS) of HRQoL [49]. Similarly to Puig-Ribera et. al [13] and this

Table 2 Immediate and long-term change in well-being associated with participation in a physical activity workplace program

\begin{tabular}{|c|c|c|c|c|c|c|c|c|c|c|}
\hline & & \multirow[t]{2}{*}{ Baseline } & \multirow{2}{*}{$\begin{array}{l}\text { Four- } \\
\text { month }\end{array}$} & \multirow{2}{*}{$\begin{array}{l}\text { Twelve- } \\
\text { month }\end{array}$} & \multicolumn{3}{|c|}{ Baseline to four-months } & \multicolumn{3}{|c|}{ Baseline to eight-months post-program } \\
\hline & & & & & Mean change & $(95 \% \mathrm{Cl})$ & P-value & Mean change & $(95 \% \mathrm{Cl})$ & P-value ${ }^{a}$ \\
\hline Mean (SD) & 407 & $60.1(19.1)$ & $63.6(18.6)$ & $63.4(18.8)$ & 3.5 & $(2.2,4.9)$ & $<0.001$ & 3.4 & $(2.0,4.8)$ & $<0.001$ \\
\hline \multirow[t]{2}{*}{ Positive well-being (\%) } & 407 & 74.7 & 80.8 & 77.2 & 6.2 & OR: 1.96 & $<0.001$ & 2.5 & OR: 1.24 & 0.1 \\
\hline & & & & & & $(1.48,2.60)$ & & & $(0.95,1.63)$ & \\
\hline \multicolumn{11}{|c|}{ Positive baseline well-being } \\
\hline Mean (SD) & 304 & $69.3(9.8)$ & $69.0(14.6)$ & $68.4(15.7)$ & -0.3 & $(-1.4,0.8)$ & 0.6 & -0.9 & $(-2.1,0.2)$ & 0.1 \\
\hline Positive well-being (\%) & 304 & 100 & 91.4 & 86.5 & -8.6 & $(-11.5,-5.6)$ & $<0.001$ & -13.5 & $(-19.4,-75.7)$ & 0.001 \\
\hline \multicolumn{11}{|c|}{ Poor baseline well-being } \\
\hline Mean (SD) & 103 & $32.9(13.1)$ & $47.8(20.0)$ & $49.0(19.8)$ & 14.9 & $(11.7,18.0)$ & $<0.001$ & 16.1 & $(12.0,20.2)$ & $<0.001$ \\
\hline Positive well-being (\%) & 103 & 0 & 49.5 & 49.5 & 49.5 & $(39.2,59.8)$ & $<0.001$ & 49.5 & $(38.3,60.7)$ & $<0.001$ \\
\hline
\end{tabular}

${ }^{a}$ Bold highlights statistically significant results. 
Table 3 Linear regression analyses assessing potential baseline and step-count predictors of four-month well-being change

\begin{tabular}{|c|c|c|c|c|c|c|}
\hline \multirow[t]{2}{*}{ Predictor variable } & \multirow[t]{2}{*}{$\mathrm{n}$} & \multirow{2}{*}{$\begin{array}{l}\text { Crude well-being } \\
\text { change (units) }\end{array}$} & \multicolumn{2}{|l|}{ Univariable } & \multicolumn{2}{|c|}{ Multivariable model } \\
\hline & & & Well-being change (units) & $P$-value ${ }^{a}$ & Well-being change (units) & $P$-value ${ }^{a}$ \\
\hline \multicolumn{7}{|l|}{ DEMOGRAPHICS } \\
\hline Age (year) & 407 & - & -0.30 & 0.4 & -0.30 & 0.4 \\
\hline \multicolumn{7}{|l|}{ Sex } \\
\hline Female & 229 & 3.46 & Reference & & & \\
\hline Male & 178 & 3.66 & 0.20 & 0.9 & 0.23 & 0.9 \\
\hline \multicolumn{7}{|l|}{ Tertiary Education } \\
\hline Not completed & 79 & 1.11 & Reference & & & \\
\hline Completed & 328 & 4.13 & 3.02 & 0.03 & 3.03 & 0.03 \\
\hline \multicolumn{7}{|l|}{ Marital status } \\
\hline Married/de facto & 286 & 3.13 & Reference & & & \\
\hline Widowed, separated or divorced & 42 & 8.48 & 5.34 & 0.2 & 5.68 & 0.1 \\
\hline Never married & 79 & 2.43 & -0.70 & 0.7 & -1.09 & 0.7 \\
\hline \multicolumn{7}{|l|}{ PROCESS MEASURES } \\
\hline Step average per day (per 1,000 steps) & 406 & - & 0.31 & 0.002 & 0.28 & 0.004 \\
\hline
\end{tabular}

${ }^{a}$ Bold highlights statistically significant results.

current paper, a greater MCS improvement was observed in those who undertook more physical activity during the program [49]. In addition, we have observed here and in our previous paper [49], that a greater improvement in MCS or well-being was observed in those with a lower baseline level of MCS.

The strengths of this evaluation study included the large sample size and the variety of sedentary occupations within the sample $[17,52]$. The main potential limitation of this study is the lack of a control group [17]. Consequently, it is not possible to definitively conclude that improvements observed in this study were attributable to participation in the program $[17,83]$. However there is no priori reason to expect well-being to improve over time without an intervention, and by using multiple workplaces, the potential of additional well-being-promoting influences would have

Table 4 Linear regression analyses assessing potential predictors of improving from 'poor' to 'positive' well-being at four-months

\begin{tabular}{|c|c|c|c|c|c|c|}
\hline \multirow[t]{2}{*}{ Predictor variable } & \multirow[t]{2}{*}{$\mathbf{n}$} & \multirow{2}{*}{$\begin{array}{l}\% \text { positive well-being } \\
\text { at four-months }\end{array}$} & \multicolumn{2}{|c|}{ Univariable } & \multicolumn{2}{|c|}{ Multivariable model } \\
\hline & & & OR & P-value $^{\mathrm{a}}$ & OR & P-value ${ }^{a}$ \\
\hline \multicolumn{7}{|l|}{ DEMOGRAPHICS } \\
\hline Age (year) & 103 & - & 1.39 & 0.008 & 1.40 & 0.01 \\
\hline \multicolumn{7}{|l|}{ Sex } \\
\hline Female & 59 & 50.85 & \multicolumn{2}{|c|}{ Reference } & & \\
\hline Male & 44 & 47.73 & 0.88 & 0.5 & 0.85 & 0.5 \\
\hline \multicolumn{7}{|l|}{ Tertiary Education } \\
\hline Not completed & 16 & 43.75 & \multicolumn{2}{|c|}{ Reference } & & \\
\hline Completed & 87 & 50.57 & 1.32 & 0.6 & 1.43 & 0.5 \\
\hline \multicolumn{7}{|l|}{ Marital status } \\
\hline Married/de facto & 70 & 51.43 & \multicolumn{2}{|c|}{ Reference } & & \\
\hline Widowed, separated or divorced & 11 & 72.73 & 2.52 & 0.2 & 2.76 & 0.2 \\
\hline Never married & 22 & 31.82 & 0.44 & 0.1 & 0.56 & 0.4 \\
\hline \multicolumn{7}{|l|}{ PROCESS MEASURE } \\
\hline Step average per day (per 1,000 steps) & 103 & - & 1.24 & $<0.001$ & 1.22 & $<0.001$ \\
\hline
\end{tabular}

${ }^{\mathrm{a} B o l d}$ highlights statistically significant results. 
been reduced [49]. Additionally, we tested the regression to the mean effect and determined that the change within the positive baseline well-being group was similar, if not better than, the change predicted by the regression to the mean effect. The poor baseline well-being group improved beyond the expected regression to the mean effect. Hence, immediate and long-term improvement in well-being within the poor baseline well-being group is likely to be associated with participation in the health program. Another potential limitation was the assessment of wellbeing as a secondary outcome of interest in the $\mathrm{GCC}^{\circ}$ Evaluation study which limits the extensiveness of our analysis to the available data, especially given the low prevalence of poor well-being that could be improved via participation in the program. We suggest that future research ensure a sufficient number of participants categorised as having poor well-being to better assess the relationship between well-being and program participation. An additional potential limitation is the lack of assessment of team, program and workplace characteristics, as well as productivity outcomes such as absenteeism, which are not available to assess as predictors in this analysis [54] and these could be explored further in future studies. An important next step is to identify the pathway to the improved mental health, by assessing the influence of specific program characteristics. Another potential limitation is the possible selection bias associated with workplace recruitment, individual recruitment and participant retention. Although enrolees were representative of Australian adults at baseline [52], the healthy volunteer effect may provide healthier employees at the cessation of the evaluation, twelve months from baseline. A healthier, more motivated cohort would be more likely to comply with the health program (overestimating the health benefits) [17] but a greater proportion of a healthier cohort would already be meeting health guidelines at baseline (underestimating the general health benefits of participation due to ceiling effects) [17]. However, selection bias is unlikely to substantially affect the interrelationships between predictors and well-being change. Finally, not obtaining pre-intervention step count is a limitation of this evaluation. At the initiation of the study it was thought that providing a pedometer prior to the initiation of a health program could be confusing to participants. As discussed in this paper, pedometer programs are generally based on Social Cognitive Theory, where self-efficacy is the main driver to positive physical activity and health behaviour change. Hence, provision of a pedometer prior to the initiation of the health program could inadvertently encourage participants to start monitoring their steps and increasing their physical activity. Hence, we felt that obtaining pre-intervention step count may have introduced bias.

\section{Conclusions}

This study is the first to assess the WHO-5 Well-being Index in a working adult population and is the first to assess general well-being, rather than psychological factors specifically related to physical health, in a pedometerbased workplace health program evaluation. At baseline we observed that three quarters of employees were achieving positive well-being scores at baseline. Clinically relevant benefits associated with participation in the health program were observed in the other quarter that had poor well-being at baseline. In addition to anthropometric and biomedical benefits that have been previously observed, psychosocial benefits also appear to be associated with participation in this four-month, pedometer-based, physical activity, workplace health program. These results suggest that a health program such as this which incorporates both physical activity and team involvement has the potential to improve well-being, especially in those who have poor well-being and actively participate in the health program.

\section{Additional files}

\section{Additional file 1: Effects of regression to the mean on changes in the WHO-Five Well-being Index by baseline well-being sub-groups. \\ Additional file 2: Sensitivity analysis of immediate and long-term change in well-being: complete case data. \\ Additional file 3: Linear regression analyses assessing potential predictors of improving from 'poor' to 'positive' well-being at four-months. \\ Additional file 4: Linear regression analyses assessing potential predictors of improving from 'poor' to 'positive' well-being at twelve-months.}

\section{Competing interests}

This data was collected as part of the Global Corporate Challenge ${ }^{\circledR}$ Evaluation Study conducted through Monash University. We would like to acknowledge the Australian Research Council (ARC) and the Foundation for Chronic Disease Prevention ${ }^{\text {TM }}$ in the Workplace, which is associated with the Global Corporate Challenge ${ }^{\circledast}$, for partially funding this study. The study design; analysis and interpretation of data; the writing of the manuscript; and the decision to submit the manuscript for publication were solely at the discretion of the Monash researchers, independent of GCC ${ }^{\circledR}$ or The

Foundation's involvement. RFP was supported by an Australian Postgraduate Award and a Monash Departmental Scholarship and is now funded by a NHMRC ECR Fellowship. EW is supported by an Australian Postgraduate and Baker IDI Heart and Diabetes Institute Bright Sparks Top-up Award. AP is funded by a VicHealth Public Health Fellowship and an NHMRC Career Development Award. The authors declare that they have no further competing interests.

\section{Authors' contributions}

RFP and AP undertook the study design and oversaw the data collection for the project. RFP takes responsibility for the integrity of the data and the accuracy of the data analysis. RFP, RW and AP contributed to the statistical data analysis. RFP, RW, EW \& AP contributed to the critical interpretation of the data. All authors contributed to the final version of the paper and have read, as well as, approved the final manuscript.

\section{Acknowledgements}

We thank all the participants and workplaces in the study. We are also grateful for the support and help of Maximillian De Courten and Margaret 
Brand. MdC assisted with conception of the GCC Evaluation with the funding previously described and is affiliated with Victoria University, Australia. MB assisted with the acquisition of data with the funding previously described and is affiliated with Monash University, Australia.

\section{Author details}

${ }^{1}$ BakerIDI Heart and Diabetes Institute, Melbourne, Australia. ${ }^{2}$ Department of Epidemiology \& Preventive Medicine, School of Public Health and Preventive Medicine, Monash University, Melbourne, Australia. ${ }^{3}$ Department of Epidemiology, Erasmus MC University Medical Center, Rotterdam, The Netherlands.

Received: 15 May 2014 Accepted: 5 August 2014

Published: 15 September 2014

\section{References}

1. World Health Organization (WHO): Basic documents. Fourty-fifth edition, Supplement October 2006. Geneva: WHO; 2006. Accessed 22nd Oct 2013 [www.who.int/governance/eb/who_constitution_en.pdf]

2. Hamer M: Psychosocial stress and cardiovascular disease risk: the role of physical activity. Psychosom Med 2012, 74(9):896-903.

3. Guszkowska M: [Effects of exercise on anxiety, depression and mood] Wplyw cwiczen fizycznych na poziom leku i depresji oraz stany nastroju. Psychiatr Pol 2004, 38(4):611-620.

4. Brown HE, Gilson ND, Burton NW, Brown WJ: Does physical activity impact on presenteeism and other indicators of workplace well-being? Sports Med 2011, 41(3):249-262

5. Peluso MA, de Andrade LH G: Physical activity and mental health: the association between exercise and mood. Clin (Sao Paulo) 2005, 60(1):61-70

6. Berchtold NC, Castello N, Cotman CW: Exercise and time-dependent benefits to learning and memory. Neuroscience 2010, 167(3):588-597.

7. Mitoma M, Yoshimura R, Sugita A, Umene W, Hori H, Nakano H, Ueda N, Nakamura J: Stress at work alters serum brain-derived neurotrophic factor (BDNF) levels and plasma 3-methoxy-4-hydroxyphenylglycol (MHPG) levels in healthy volunteers: BDNF and MHPG as possible biological markers of mental stress? Prog Neuropsychopharmacol Biol Psychiatry 2008, 32(3):679-685

8. Ikenouchi-Sugita A, Yoshimura R, Sugita K, Hori H, Yamada K, Sakaue M, Nakamura J: The effects of a walking intervention on depressive feelings and social adaptation in healthy workers. J Uoeh 2013, 35(1):1-8

9. Penedo FJ, Dahn JR: Exercise and well-being: a review of mental and physical health benefits associated with physical activity. Curr Opin Psychiatr 2005, 18(2):189-193.

10. Eime RM, Young JA, Harvey JT, Charity MJ, Payne WR: A systematic review of the psychological and social benefits of participation in sport for adults: informing development of a conceptual model of health through sport. Int J Behav Nutr Phys Act 2013, 10:135.

11. Conn VS: Depressive symptom outcomes of physical activity interventions: meta-analysis findings. Ann Behav Med 2010, 39(2):128-138.

12. Martin A, Sanderson K, Cocker F: Meta-analysis of the effects of health promotion intervention in the workplace on depression and anxiety symptoms. Scand J Work Environ Health 2009, 35(1):7-18.

13. Puig-Ribera A, McKenna J, Gilson N, Brown WJ: Change in work day step counts, wellbeing and job performance in Catalan university employees: a randomised controlled trial. Promot Educ 2008, 15(4):11-16.

14. World Health Organization (WHO): The workplace as a setting for interventions to improve diet and promote physical activity. http://www.who.int/dietphysicalactivity/Quintiliani-workplace-as-setting. pdf Accessed 30/05/2014. Edited by Quintiliani L, Sattelmair J, Sorensen G Geneva: WHO; 2008

15. World Health Organization (WHO): Global strategy on diet, physical activity and health. Edited by the 57th World Health Assembly. Geneva: WHO; 2004.

16. Freak-Poli RL, Cumpston M, Peeters A, Clemes SA: Workplace pedometer interventions for increasing physical activity. Cochrane Database Syst Rev 2013, 4, CD009209.

17. Freak-Poli R, Wolfe R, Backholer K, de Courten M, Peeters A: Impact of a pedometer-based workplace health program on cardiovascular and diabetes risk profile. Prev Med 2011, 53(3):162-171.
18. Bravata D, Smith-Spangler C, Sundaram V, Gienger A, Lin N, Lewis R, Stave C, Olkin I, Sirard J: Using pedometers to increase physical activity and improve health: a systematic review. JAMA 2007, 298(19):2296-2304.

19. Speck BJ, Looney SW: Effects of a minimal intervention to increase physical activity in women: daily activity records. Nurs Res 2001, 50(6):374-378.

20. Croteau KA: Strategies used to increase lifestyle physical activity in a pedometer-based intervention. J Allied Health 2004, 33(4):278-281.

21. Murphy MH, Murtagh EM, Boreham CA, Hare LG, Nevill AM: The effect of a worksite based walking programme on cardiovascular risk in previously sedentary civil servants [NCT00284479]. BMC Public Health 2006, 6:136.

22. Thomas L, Williams M: Promoting physical activity in the workplace: using pedometers to increase daily activity levels. Health Promot J Austr 2006, 17(2):97-102.

23. Gilson N, McKenna J, Cooke C, Brown W: Walking towards health in a university community: a feasibility study. Prev Med 2007, 44(2):167-169.

24. Haines DJ, Davis L, Rancour P, Robinson M, Neel-Wilson T, Wagner S: A pilot intervention to promote walking and wellness and to improve the health of college faculty and staff. J Am Coll Health 2007, 55(4):219-225.

25. Low D, Gramlich M, Engram BW: Self-paced exercise program for office workers: impact on productivity and health outcomes. Aaohn J 2007, 55(3):99-105.

26. Faghri PD, Omokaro C, Parker C, Nichols E, Gustavesen S, Blozie E: E-technology and pedometer walking program to increase physical activity at work. J Prim Prev 2008, 29(1):73-91.

27. Gemson DH, Commisso R, Fuente J, Newman J, Benson S: Promoting weight loss and blood pressure control at work: impact of an education and intervention program. J Occup Environ Med 2008, 50(3):272-281.

28. Naito M, Nakayama T, Okamura T, Miura K, Yanagita M, Fujieda Y, Kinoshita F, Naito Y, Nakagawa H, Tanaka T, Ueshima H: Effect of a 4-year workplace-based physical activity intervention program on the blood lipid profiles of participating employees: the high-risk and population strategy for occupational health promotion (HIPOP-OHP) study. Atherosclerosis 2008, 197(2):784-790

29. Dishman RK, Vandenberg RJ, Motl RW, Wilson MG, Dejoy DM: Dose relations between goal setting, theory-based correlates of goal setting and increases in physical activity during a workplace trial. Health Educ Res 2009, 25(4):620-631.

30. Gilson ND, Puig-Ribera A, McKenna J, Brown WJ, Burton NW, Cooke CB: Do walking strategies to increase physical activity reduce reported sitting in workplaces: a randomized control trial. Int I Behav Nutr Phys Act 2009, 6:43.

31. Racette SB, Deusinger SS, Inman CL, Burlis TL, Highstein GR, Buskirk TD, Steger-May K, Peterson LR: Worksite Opportunities for Wellness (WOW): effects on cardiovascular disease risk factors after 1 year. Prev Med 2009, 49(2-3):108-114

32. Farag NH, Moore WE, Thompson DE, Kobza CE, Abbott K, Eichner JE: Evaluation of a community-based participatory physical activity promotion project: effect on cardiovascular disease risk profiles of school employees. BMC Public Health 2010, 10(1):313.

33. Kwak L, Kremers SP, Candel MJ, Visscher TL, Brug J, van Baak MA: Changes in skinfold thickness and waist circumference after 12 and 24 months resulting from the NHF-NRG In Balance-project. Int I Behav Nutr Phys Act 2010, 7:26.

34. Warren BS, Maley M, Sugarwala LJ, Wells MT, Devine CM: Small steps are easier together: a goal-based ecological intervention to increase walking by women in rural worksites. Prev Med 2010, 50(5-6):230-234.

35. Aittasalo M, Milunpalo S, Suni J: The effectiveness of physical activity counseling in a work-site setting. A randomized, controlled trial. Patient Educ Couns 2004, 55(2):193-202.

36. Behrens TK, Domina L, Fletcher GM: Evaluation of an employer-sponsored pedometer-based physical activity program. Percept Mot Skills 2007, 105(3 Pt 1):968-976.

37. De Cocker KA, De Bourdeaudhuij IM, Cardon GM: The effect of a multi-strategy workplace physical activity intervention promoting pedometer use and step count increase. Health Educ Res 2009, 25(4):608-619.

38. Speck RM, Hill RK, Pronk NP, Becker MP, Schmitz KH: Assessment and outcomes of healthpartners 10,000 steps(R) program in an academic work site. Health Promot Pract 2009, 11(5):741-750.

39. Maruyama C, Kimura M, Okumura H, Hayashi K, Arao T: Effect of a worksite-based intervention program on metabolic parameters in middle-aged male white-collar workers: a randomized controlled trial. Prev Med 2010, 51(1):11-17. 
40. Bauman A, Bellew B, Vita P, Brown W, Owen N: Getting Australia active: towards better practice for the promotion of physical activity. Melbourne, Australia: National Public Health Partnership. In; 2002.

41. Culos-Reed C, Gyurcsik N, Brawley L: Using theories of motivated behaviour to understand physical activity. In Handbook of Sport Psychology. Edited by Singer RN HH, Janelle CM. New York: John Wiley \& Sons, Inc; 2001:695-717.

42. Freak-Poli R, Cumpston M, Peeters A, Clemes S: Workplace pedometer interventions for increasing physical activity (Protocol). Cochrane Database Syst Rev 2011(7):CD009209.

43. Lemon SC, Zapka J, Li W, Estabrook B, Rosal M, Magner R, Andersen V, Borg A, Hale J: Step ahead a worksite obesity prevention trial among hospital employees. Am J Prev Med 2010, 38(1):27-38.

44. Lubans DR, Morgan PJ, Collins CE, Warren JM, Callister R: Exploring the mechanisms of weight loss in the SHED-IT intervention for overweight men: a mediation analysis. Int J Behav Nutr Phys Act 2009, 6:76

45. Prabhakaran D, Jeemon P, Goenka S, Lakshmy R, Thankappan KR, Ahmed F, Joshi PP, Mohan BV, Meera R, Das MS, Ahuja RC, Saran RK, Chaturvedi V, Reddy KS: Impact of a worksite intervention program on cardiovascular risk factors: a demonstration project in an Indian industrial population. J Am Coll Cardiol 2009, 53(18):1718-1728.

46. Prodaniuk TR, Plotnikoff RC, Spence JC, Wilson PM: The influence of self-efficacy and outcome expectations on the relationship between perceived environment and physical activity in the workplace. Int J Behav Nutr Phys Act 2004, 1(1):7.

47. Tudor-Locke C: Promoting lifestyle physical activity: experiences with the first step program. Am J Lifestyle Med 2009, 3(1 Suppl):508-548.

48. Egan M, Tannahill C, Petticrew M, Thomas S: Psychosocial risk factors in home and community settings and their associations with population health and health inequalities: a systematic meta-review. BMC Public Health 2008, 8:239

49. Freak-Poli R, Harding J, Backholer K, Peeters A: Changes in health-related quality of life amongst participants in a four-month pedometer-based workplace health program. J Phys Act Health 2013, 10(4):533-543.

50. Touger-Decker R, Denmark R, Bruno M, O'Sullivan-Maillet J, Lasser N: Workplace weight loss program; comparing live and internet methods. J Occup Environ Med 2010, 52(11):1112-1118.

51. Freak-Poli R, Wolfe R, Brand M, de Courten M, Peeters A: Eight-month postprogram completion: change in risk factors for chronic disease amongst participants in a 4-month pedometer-based workplace health program. Obesity (Silver Spring) 2013, 21(9):E360-E368.

52. Freak-Poli $\mathrm{R}$, Wolfe $\mathrm{R}$, Peeters $\mathrm{A}$ : Risk of cardiovascular disease and diabetes in a working population with sedentary occupations. J Occup Environ Med 2010, 52(11):1132-1137.

53. Freak-Poli R, Backholer K, Peeters A: Daily step-count and change in waist circumference during a workplace pedometer program. Open J Prev Med 2012, 2(2):249-256.

54. Freak-Poli RL, Wolfe R, Walls H, Backholer K, Peeters A: Participant characteristics associated with greater reductions in waist circumference during a four-month, pedometer-based, workplace health program. BMC Public Health 2011, 11(1):824.

55. Ng W, Freak-Poli R, Peeters A: The Prevalence and Characteristics Associated With Excessive Daytime Sleepiness Among Australian Workers. J Occup Environ Med 2014, [Epub ahead of print].

56. The Global Corporate Challenge. [http://www.gettheworldmoving.com/ what-is-the-gcc]

57. World Health Organization (WHO): The WHO STEPwise approach. Surveillence of risk factors for noncommunicable diseases: Step 1, 2 \& 3 Switzerland: WHO; 2002.

58. Dunstan DW, Zimmet PZ, Welborn TA, Cameron AJ, Shaw J, de Courten M, Jolley D, McCarty DJ: The Australian Diabetes, Obesity and Lifestyle Study (AusDiab)-methods and response rates. Diabetes Res Clin Pract 2002, 57(2):119-129.

59. Giles GG, English DR: The Melbourne collaborative cohort study. IARC Sci Publ 2002, 156:69-70.

60. Ball K, Brown W, Crawford D: Who does not gain weight? Prevalence and predictors of weight maintenance in young women. Int J Obes Relat Metab Disord 2002, 26(12):1570-1578.

61. WHO-Five Well-being Index (WHO-5). [www.who-5.org]

62. Bech P: Quality of life in the psychiatric patient. London: Mosby-Wolfe; 1998.
63. Bech P: Male depression: stress and aggression as pathways to major depression. In Depression: Social and economic timebomb. London: BMJ Books; 2001:63-66.

64. Shea S, Skovlund S, Bech P, Kalo I, Home P: Routine assessment of psychological well-being in people with diabetes - validation of the WHO-5 Well-being Index in six countries. In 18th International Diabetes Federation Congress. Paris: Diabetologia; 2003. A88 [no.245].

65. Lowe B, Spitzer R, Grafe K, Kroenke K, Quenter A, Zipfel S, Buchholz C, Witte S, Herzog W: Comparative validity of three screening questionnaires for DSM-IV depressive disorders and physicians' diagnoses. J Affect Disord 2004, 78:131-140.

66. Australian Institute of Health and Welfare (AlHW): Australia's health 2008. Cat. no. AUS 99. Canberra: AlHW; 2008.

67. Commonwealth Government Department of Health and Aged Care (DHAC): National physical activity guidelines for Australians. Canberra: DHAC; 1999.

68. Royal Australian College of General Practitioners: National Preventive and Community Medicine Committee: Guidelines for preventive activities in general practice, 7th edition. Victoria: The Royal Australian College of General Practitioners; 2009.

69. National Health and Medical Research Council (NHMRC): Food for health: Dietary Guidelines for all Australians. Canberra: NHMRC; 2003.

70. Glymour MM, Weuve J, Berkman LF, Kawachi I, Robins JM: When is baseline adjustment useful in analyses of change? An example with education and cognitive change. Am J Epidemiol 2005, 162(3):267-278.

71. Stata Corporation: College Station. TX: www.stata.com.

72. Linden $\mathrm{A}$ : Estimating the effect of regression to the mean in health management programs. Dis Manag Health Outcomes 2007, 15(1):7-12.

73. Delaney L, Doyle O, Mckenzie K, Wall P: The distribution of wellbeing in Ireland. Irish J Psychol Med 2009, 26:119-126.

74. Aujla N, Abrams KR, Davies MJ, Taub N, Skinner TC, Khunti K: The prevalence of depression in white-European and South-Asian people with impaired glucose regulation and screen-detected type 2 diabetes mellitus. PLoS One 2009, 4(11):e7755.

75. Hajos TR, Pouwer F, de Grooth R, Holleman F, Twisk JW, Diamant M, Snoek FJ: The longitudinal association between glycaemic control and health-related quality of life following insulin therapy optimisation in type 2 diabetes patients. A prospective observational study in secondary care. Qual Life Res 2011, 21(8):1359-1365.

76. Due-Christensen M, Zoffmann V, Hommel E, Lau M: Can sharing experiences in groups reduce the burden of living with diabetes, regardless of glycaemic control? Diabet Med 2011, 29(2):251-256.

77. Newnham EA, Hooke GR, Page AC: Monitoring treatment response and outcomes using the World Health Organization's Wellbeing Index in psychiatric care. J Affect Disord 2010, 122(1-2):133-138.

78. Conn VS, Hafdahl AR, Brown LM: Meta-analysis of quality-of-life outcomes from physical activity interventions. Nurs Res 2009, 58(3):175-183.

79. Chu AH, Koh D, Moy FM, Muller-Riemenschneider F: Do workplace physical activity interventions improve mental health outcomes? Occup Med (Lond) 2014, 64(4):235-245.

80. Christie J, O'Halloran P, Caan W, Cardwell C, Young T, Rao M: Workplacebased organisational interventions to prevent and control obesity by improving dietary intake and/or increasing physical activity (Protocol). Cochrane Database Syst Rev 2010, (6):CD008546.

81. Centers for Disease Control and Prevention Health-Related Quality-of-Life 14-Item Measure. [http://www.cdc.gov/hrqol/hrqol14_measure.htm]

82. Saris-Baglama R, Dewey C, Chisholm G, Plumb E, King J, Kosinski M, BJorner JB, Ware JE: QualityMetric Health Outcomes Scoring Software 3.0 User's Guide. Lincoln, USA: QualityMetric Incorporated; 2007.

83. Chan CB, Ryan DA, Tudor-Locke C: Health benefits of a pedometer-based physical activity intervention in sedentary workers. Prev Med 2004, 39(6):1215-1222.

\section{doi:10.1186/1471-2458-14-953}

Cite this article as: Freak-Poli et al:: Change in well-being amongst participants in a four-month pedometer-based workplace health program. BMC Public Health 2014 14:953. 